\title{
MERCURY OXIDATION IN CATALYSTS USED FOR SELECTIVE REDUCTION OF NO $($ (SCR) IN OXY-FUEL COMBUSTION
}

Nuria Fernández-Miranda, M. Antonia Lopez-Anton*, Mercedes Díaz-Somoano, M. Rosa Martínez-Tarazona

Instituto Nacional del Carbón (CSIC), Francisco Pintado Fe, 26, 33011, Oviedo, Spain

*Corresponding author:

Phone: +34 985119090

Fax: +34 985297662

Email: marian@incar.csic.es 


\begin{abstract}
Emissions of mercury $(\mathrm{Hg})$ and their control are a well-known problem for conventional coal combustion power plants but they still represent a challenge for relatively new technologies such as the oxy-combustion. In oxy-fuel combustion systems it is important that $\mathrm{Hg}$ be in its oxidized form $\left(\mathrm{Hg}^{2+}\right)$ because in the form of elemental mercury $\left(\mathrm{Hg}^{0}\right)$, it can damage the $\mathrm{CO}_{2}$ compression units. In conventional air combustion some catalysts used in selective catalytic reduction (SCR) of NOx could also co-benefit $\mathrm{Hg}$ oxidation. This study evaluates the oxidation of $\mathrm{Hg}$ in the presence of several SCR catalysts under an oxy-combustion atmosphere focusing on the main differences with conventional air coal combustion. In the experimental conditions of this study, a higher mercury oxidation was observed in the $\mathrm{CO}_{2}$-enriched atmosphere due to the fact that in this atmosphere the conversion of NOx was lower, which resulted in a higher concentration of $\mathrm{NO}$ and $\mathrm{NO}_{2}$ free to homogeneously oxidize mercury. In oxy-combustion conditions the high amount of $\mathrm{CO}_{2}$ and $\mathrm{H}_{2} \mathrm{O}$ present may block the active sites for mercury adsorption. Moreover, the differences between the active sites of catalysts based on $\mathrm{V} / \mathrm{W} / \mathrm{TiO}_{2}$ and $\mathrm{Fe} /$ Zeolite with/without $\mathrm{Mn}$ as doping agent were eclipsed by the effect of the flue gas composition
\end{abstract}

Keywords: mercury; catalysts; oxy-combustion 


\section{Introduction}

During the last decade, oxy-fired coal power plants have emerged as a promising technology for $\mathrm{CO}_{2}$ capture. In oxy-combustion plants, coal is burned with a mixture of $\mathrm{O}_{2}$ and recirculated flue gas, instead of air. This results in a flue gas stream with a high concentration of $\mathrm{CO}_{2}$, suitable for purification, compression and storage. Despite the significant amount of fundamental and experimental research carried out on the oxycombustion process [1-2], some uncertainties, such as the behavior of mercury and its control, still remain unsolved. Under oxy-fuel conditions higher $\mathrm{Hg}$ concentrations than in air-firing are to be expected [3-4]. High concentrations of mercury are a matter of concern not only because they are a danger to the environment but also because they cause technological problems as $\mathrm{Hg}$ can corrode the Al-alloys in the $\mathrm{CO}_{2}$ compression units [5-6].

During combustion, mercury present in coal evaporates as elemental mercury $\left(\mathrm{Hg}^{0}\right)$, but as the flue gas cools, it is partially transformed into oxidized species $\left(\mathrm{Hg}^{2+}\right)$. The distribution, speciation and capture of $\mathrm{Hg}$ in a power plant depend on its content in the coal, the combustion conditions, halogen and sulfur species in the gas stream, unburned particles in fly ashes, etc. It is well known that $\mathrm{Hg}^{2+}$ can be retained in the flue gas desulphurization (FGD) units and particulate control systems and that $\mathrm{Hg}^{0}$ is more difficult to remove due to its insolubility in water and high volatility. $\mathrm{Hg}$ speciation and capture in oxy-fuel conditions may differ from coal combustion with air due to the increase in $\mathrm{H}_{2} \mathrm{O}, \mathrm{HCl}, \mathrm{SOx}$ and $\mathrm{Hg}$ concentrations in the flue gas and the change in $\mathrm{NOx}$ concentrations caused by the absence of air-borne $\mathrm{N}_{2}$ in oxy-combustion mode [7-8]. The presence of $\mathrm{H}_{2} \mathrm{O}, \mathrm{HCl}, \mathrm{NOx}$ and $\mathrm{SOx}$ in the gas may improve the homogeneous oxidation of $\mathrm{Hg}$ depending on their relative proportions and concentrations [9]. The emissions control units installed in power stations are also a very important factor in 
controlling Hg. FGD units, filters and selective catalytic reduction (SCR), installed for the control of SOx, particulate matter and NOx, respectively [10-11], may play an important role in mercury behaviour and capture.

This study is focused on evaluating the influence of some of the catalysts commonly used for SCR on $\mathrm{Hg}$ behavior in oxy-fuel combustion conditions.

The goal of SCR technology [12] is to reduce NOx to nitrogen and water by injecting $\mathrm{NH}_{3}$ according to the following reactions:

$$
\begin{aligned}
& 4 \mathrm{NO}+4 \mathrm{NH}_{3}+\mathrm{O}_{2} \leftrightarrow 4 \mathrm{~N}_{2}+6 \mathrm{H}_{2} \mathrm{O} \\
& 2 \mathrm{NO}_{2}+4 \mathrm{NH}_{3}+\mathrm{O}_{2} \leftrightarrow 3 \mathrm{~N}_{2}+6 \mathrm{H}_{2} \mathrm{O}
\end{aligned}
$$

The reaction occurs over a catalyst, usually at $300-400^{\circ} \mathrm{C}$. A co-benefit of SCR implementation is that it is also effective for oxidizing $\mathrm{Hg}^{0}$ to $\mathrm{Hg}^{2+}$ [13-14] favoring its retention in fly ashes and FGD systems, and in the case of the oxy-combustion, avoiding the corrosion caused by $\mathrm{Hg}^{0}$ in the compression units. A wide range of SCR catalysts are available. Most of them are prepared by using ceramic materials as supports, such as $\mathrm{TiO}_{2}, \mathrm{Fe}_{2} \mathrm{O}_{3}, \mathrm{Al}_{2} \mathrm{O}_{3}$ or zeolite, and active catalytic components such as oxides of base metals (such as V, Cr, Mn, Co, W and Mo) or noble metals (Pt, Pd) [15]. There is a wide body of research focused on improving the activity of the catalyst [1617], but there is a lack of knowledge on the behavior of SCR for emerging applications such as oxy-combustion [18-19]. An increase in the $\mathrm{CO}_{2}$ concentration is not considered to have any effect on the behavior of the catalyst. However, an increase in $\mathrm{SO}_{2}$ and $\mathrm{SO}_{3}$ concentration in the flue gas of oxy-combustion [10, 20-22] can undermine the performance of the catalyst. $\mathrm{SO}_{3}$ is known to form a sticky and corrosive ammonium bisulfate when $\mathrm{NH}_{3}$ is added [23-24] and therefore, severe clogging of the catalyst can be expected. In a similar way, water vapor can contribute to reducing the number of available active sites on the surface of the catalyst [17]. Changes in the flue gas 
composition and the effectiveness of the SCR system can modify the speciation of mercury [25], thereby affecting mercury retention during the oxy-combustion process. Wang et al. [11] evaluated the efficiency of a $\mathrm{V}_{2} \mathrm{O}_{5}-\mathrm{WO}_{3} / \mathrm{TiO}_{2}$ catalyst for $\mathrm{Hg}^{0}$ removal in a $\mathrm{CO}_{2}$-enriched gas containing different concentrations of $\mathrm{O}_{2}, \mathrm{CO}_{2}, \mathrm{NO}$ and $\mathrm{NH}_{3}$. They recorded a high level of removal at $250-350^{\circ} \mathrm{C}$ for both $\mathrm{Hg}^{0}$ and $\mathrm{NO}$, attributing the removal of $\mathrm{Hg}^{0}$ mainly to $\mathrm{Hg}$ oxidation. The degree of $\mathrm{Hg}$ oxidation throughout the SCR unit can also vary in the presence of other gases such as $\mathrm{SOx}, \mathrm{HCl}$ and $\mathrm{H}_{2} \mathrm{O}$. Mitsui et al [3] found that in a oxy-fuel combustion atmosphere, $\mathrm{Hg}$ oxidation throughout the SCR increased as the incoming $\mathrm{HCl}$ concentration increased, although the effect of $\mathrm{HCl}$ was similar to that of $\mathrm{HCl}$ in air combustion. Zhuang et al. [26] also analyzed the individual effects of $\mathrm{HCl}, \mathrm{SO}_{2}$ and $\mathrm{SO}_{3}$ and concluded that sulfur species compete with $\mathrm{HCl}$ for adsorption sites on the SCR catalyst surface, reducing its capacity for $\mathrm{Hg}$ oxidation. Although the results described help in predicting the behavior of $\mathrm{Hg}$ in a SCR catalyst, more studies are necessary in order to confirm whether Hg oxidation takes place across a SCR unit in oxy-combustion conditions where not only $\mathrm{CO}_{2}$ but also $\mathrm{H}_{2} \mathrm{O}$ is present in high concentrations, and to reveal possible differences with an air combustion system.

The objective of the present work is to evaluate the oxidation and possible capture of $\mathrm{Hg}$ by SCR catalysts $\left(\mathrm{V} / \mathrm{W} / \mathrm{TiO}_{2}\right.$ and $\mathrm{Fe} /$ Zeolite $)$ under a simulated flue gas of oxycombustion where all the main possible gases are present $\left(\mathrm{CO}_{2}, \mathrm{SOx}, \mathrm{HCl}, \mathrm{O}_{2}, \mathrm{NOx}\right.$, $\mathrm{H}_{2} \mathrm{O}, \mathrm{NH}_{3}$ and $\mathrm{N}_{2}$ ).

\section{Experimental part}

\subsection{Catalysts}


The SCR catalysts were prepared by the Johnson Matthey technology center using an impregnation method in which the active SCR base metal component $(\mathrm{Fe}, \mathrm{V}$ and W) was first impregnated on a powder support $\left(\mathrm{TiO}_{2}\right.$ and Zeolite) and then dried and calcined at $500^{\circ} \mathrm{C}$. The powder catalysts were also aged hydrothermally at $550^{\circ} \mathrm{C}$ for $48 \mathrm{hrs}$ to simulate a de-greening phase or to partially age the catalysts. The effect of a separate mercury oxidation component on the powder-impregnated SCR catalysts was investigated by doping the standard SCR catalyst samples with manganese $(\mathrm{Mn})$. The samples were characterized by different methods including surface area and porosity, XPS, XRD, $\mathrm{H}_{2}$ TPR, $\mathrm{NH}_{3}$ TPD and RAMAN spectroscopy. The results obtained have been published in the RFCR-CT-2007-00007 project report [27].

\subsection{Experimental device}

The capacity of the catalysts for NOx reduction and $\mathrm{Hg}$ retention and oxidation was evaluated in the experimental laboratory scale device illustrated in Figure 1 (A) and Figure 1 (B), respectively. The device consists of: (1) a gas blending station equipped with mass flow controllers for preparing the different gas compositions (Table 1) focusing on the gas composition that simulates a typical oxy-combustion atmosphere $\left(64 \% \mathrm{CO}_{2}, 20 \% \mathrm{~N}_{2}, 12 \% \mathrm{H}_{2} \mathrm{O}, 4 \% \mathrm{O}_{2}, 1000 \mathrm{ppm} \mathrm{SO}_{2}, 600\right.$ ppm NO, 100 ppm $\mathrm{NO}_{2}$ and $25 \mathrm{ppm} \mathrm{HCl}$ ); (2) a glass reactor (length, $500 \mathrm{~mm}$; diameter, $25 \mathrm{~mm}$ ) where the catalyst bed is situated. The bed was prepared by mixing $0.08 \mathrm{~g}$ of catalyst with $0.40 \mathrm{~g}$ of sand in order to avoid an excess of pressure in the system. The sand was previously tested showing not mercury retention and oxidation. The reactor was kept at $350^{\circ} \mathrm{C}$. The total volume of flow gases that passed through the catalyst bed was $0.5 \mathrm{~L} \cdot \mathrm{min}^{-1}$; (3) a TESTO 350 Gas Analyzer to evaluate the reduction of NOx (Figure 1 (A)); (4) a calibrated permeation tube (VICI Metronic) placed inside a glass "U" tube immersed in a water 
bath to obtain $100 \mu \mathrm{g} \mathrm{m}^{-3}$ of $\mathrm{Hg}^{0}$ in gas phase and; (5) a continuous mercury analyzer (VM-3000) that monitored the signal of $\mathrm{Hg}^{0}$ at the outlet of the reactor (Figure 1 (B)). The $\mathrm{Hg}^{2+}$ was captured by an ion exchanger resin (Dowex $1 \mathrm{x} 8$ ), suitable for the selective capture of $\mathrm{Hg}^{2+}$ species [28]. The resin was conditioned with a solution of $\mathrm{HCl}: \mathrm{H}_{2} \mathrm{O}(1: 1)$ at $90^{\circ} \mathrm{C}$ for 30 minutes and then filtered and dried. The resin was placed prior to the $\mathrm{Hg}^{0}$ continuous analyzer in such a way that the total mercury concentration was balanced. The $\mathrm{Hg}^{2+}$ in the resin and in the condensed water at the end of the experiments and the mercury retained in the catalyst were measured using an automatic mercury analyzer (AMA 254).

\section{Results and discussion}

\subsection{Characterization and activity of the catalysts}

A summary of the most important conclusions from the characterization of the catalysts studied $\left(\mathrm{V} / \mathrm{W} / \mathrm{TiO}_{2}, \mathrm{Mn}-\mathrm{V} / \mathrm{W} / \mathrm{TiO}_{2}, \mathrm{Fe} / \mathrm{Zeolite}\right.$ and $\mathrm{Mn}-\mathrm{Fe} /$ Zeolite $)$ has already been provided in a previous work [27]. Its findings that may help to interpret the results of the present study are the following: (i) When the SCR catalysts were doped with Mn $(5-10 \mathrm{wt} \%)$ the specific surface area decreased, indicating that impregnation with metal species may have blocked or restricted access to the porous sites and (ii) analysis by XPS showed that the concentration of Mn on the surface of the Fe/Zeolite support was lower than on the $\mathrm{V} / \mathrm{W} / \mathrm{TiO}_{2}$ catalysts, suggesting that the shielding effect was greater or that more dopants were being exchanged inside the bulk of the Fe/Zeolite material. The characteristics of the catalyst doped with Mn are mentioned here because this metal was added to improve $\mathrm{Hg}$ interactions.

In Project RFCR-CT-2007-00007 [27] the catalytic activity of the SCR catalysts in the conversion of $\mathrm{NOx}$ and $\mathrm{NH}_{3}$ to $\mathrm{N}_{2}+\mathrm{H}_{2} \mathrm{O}$ was also investigated. In that study, the 
tests were carried out in conditions of 200 ppm NOx, 200 ppm $\mathrm{NH}_{3}, 12 \% \mathrm{O}_{2}, 4.5 \%$

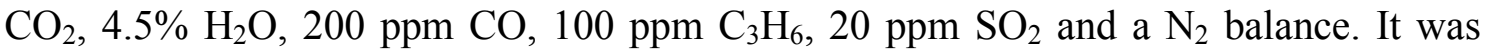
found that the selective catalytic reduction performances of the fresh zeolite and $\mathrm{V} / \mathrm{W} / \mathrm{TiO}_{2}$ catalysts were very similar ( $\sim 95 \%$ NOx conversion). However, the Fe/zeolite had reduced SCR activity ( $\sim 55 \%)$ after being doped with Mn. This may have been due to blockage of active sites and/or the exchange of metal ions which reduces the acidity of the catalysts. In the case of the $\mathrm{V} / \mathrm{W} / \mathrm{TiO}_{2}$ catalysts the addition of $\mathrm{Mn}$ had little, to no effect, on the catalytic activity as the active sites were of a different nature to those of zeolites. As expected the catalytic activity decreased after ageing [27].

In light of the above results, the $\mathrm{Hg}$ behavior across the $\mathrm{V} / \mathrm{W} / \mathrm{TiO}_{2}$ and Fe/Zeolite catalysts in an oxy-combustion atmosphere was evaluated using the experimental device described in Figure 1. Since the catalysts need to be effective for both the reduction of NOx and the oxidation of $\mathrm{Hg}^{0}$, catalytic activity for NOx reduction in these new conditions was assessed first (Figure $1(\mathrm{~A})$ ). The experiments were carried out over a period of $12 \mathrm{~h}$ using the fresh catalysts with different gas compositions, as shown in Table 1. In this way the effect of the oxy-fuel gas composition can be evaluated and the differences between an oxy-combustion and an air combustion gas composition can be identified. The catalysts achieved NOx reduction efficiencies ranging from 88 to $99 \%$ when no reactive gases were present, that is, in atmospheres that only contained $\mathrm{NO}_{2}, \mathrm{NO}, \mathrm{NH}_{3}$ and $\mathrm{O}_{2}$ (Figures 2-3) (Reactions 1 and 2). It is worth noting that, the percentages of $\mathrm{NO}$ and $\mathrm{NO}_{2}$ conversion throughout the SCR catalyst decreased greatly in the oxy-combustion atmosphere $600 \mathrm{ppm} \mathrm{NO}, 100 \mathrm{ppm} \mathrm{NO}, 4 \%$ $\mathrm{O}_{2}, 64 \% \mathrm{CO}_{2}, 20 \% \mathrm{~N}_{2}, 12 \% \mathrm{H}_{2} \mathrm{O}, 1000$ ppm $\mathrm{SO}_{2}$ and 25 ppm $\mathrm{HCl}$ plus 1000 ppm $\mathrm{NH}_{3}$, (Figures 2-3). The capacity of the catalysts to convert NOx was also lower in the atmosphere simulating conventional coal combustion with air. The explanation for this 
low reactivity must be sought in the reactive gases. The deactivating effect of $\mathrm{SO}_{2}$ on SCR catalysts, mainly in those supported on zeolite, is well known [17, 24], but it is not the only factor responsible for the deactivation of the catalyst. In fact, the reduction of NOx was lower in the oxy-combustion atmosphere than in the air combustion atmosphere (Figures 2-3), whereas the $\mathrm{SO}_{2}$ concentration and also the concentration of $\mathrm{HCl}$ were the same in both atmospheres. It appears that the different concentrations of $\mathrm{CO}_{2}$ and $\mathrm{H}_{2} \mathrm{O}$ also influence the reduction of NOx. $\mathrm{CO}_{2}$ and $\mathrm{H}_{2} \mathrm{O}$ are present in oxy-fuel combustion in concentrations that are very different to those of air combustion. To establish why the reduction of NOx decreased in oxy-combustion conditions to a greater extent than under air combustion (Figures 2-3), a series of experiments was carried out in which the concentration of $\mathrm{H}_{2} \mathrm{O}$ was varied from 6 to $12 \%$, while the $\mathrm{CO}_{2}$ content was kept at 35\%. The percentage of NOx reduction was similar in all cases. However, when the experiments were conducted in an atmosphere with 16 and $64 \% \mathrm{CO}_{2}$ but without $\mathrm{H}_{2} \mathrm{O}$, the activity of the catalyst was lower in the atmosphere with the higher $\mathrm{CO}_{2}$ concentration. It must be borne in mind that the diffusivity of $\mathrm{NOx}$ may be different in an atmosphere enriched in $\mathrm{CO}_{2}$ to what it is in $\mathrm{N}_{2}$ [29]. In fact, according to a simplified equation of Fuller et al. [30] the coefficients of diffusivity for $\mathrm{NO}$ and $\mathrm{NO}_{2}$ in an atmosphere enriched in $\mathrm{CO}_{2}$ in the experimental conditions of this study are 0.667 and $0.658 \mathrm{~cm}^{2} \mathrm{~s}^{-1}$, respectively, whereas in an atmosphere enriched in $\mathrm{N}_{2}$ they are 1.015 and $0.831 \mathrm{~cm}^{2} \mathrm{~s}^{-1}$, respectively. The conversion of NOx is a mass transfer process which will be more limited in a $\mathrm{CO}_{2}$ than in a $\mathrm{N}_{2}$ atmosphere. Also to be taken into account is the possibility that $\mathrm{CO}_{2}$ blocks, or competes for, the active sites of the catalysts, contributing, together with the acid gases, to a decrease in the efficiency of NOx conversion. $\mathrm{H}_{2} \mathrm{O}$, on the other hand, although it may also contribute to the destruction 
of the active sites of the catalyst, is not such a critical component because it is already being produced by the SCR reactions (Reactions 1-2).

\subsection{Mercury behavior in the presence of the catalysts}

To evaluate the behavior of mercury in the presence of the catalysts, experiments were carried out in a simulated oxy-combustion flue gas and under an air coal combustion atmosphere. The mercury conversion rate with SCR depends on factors such as the temperature, acid gas composition and ammonia dosing rate [31]. The effect of these parameters has been previously evaluated in the Project RFCR-CT-2007-00007 [27]. In general, it can be inferred that i) when the temperature is increased, the oxidation of mercury decreases, ii) $\mathrm{HCl}$ has a beneficial effect on mercury oxidation iii) when the $\mathrm{SO}_{2}$ concentration is increased slightly, mercury oxidation may be favored due to the higher acid load of the catalyst, making the catalysts more active for mercury oxidation and iv) a high concentration of ammonia can overload the catalysts`active sites and reduce the rate of mercury conversion. The task now is to assess the role of $\mathrm{CO}_{2}$ and $\mathrm{H}_{2} \mathrm{O}$ in the oxidation of mercury in the presence of the catalysts.

Figures 4-5 show the percentages of i) mercury $\left(\mathrm{Hg}^{0}+\mathrm{Hg}^{2+}\right)$ retained in the catalysts (i.e., Hgp), ii) the oxidized mercury in gas phase $\left(\mathrm{Hg}^{2+}\right)$, resulting from homogeneous oxidation (gas-gas interaction) and heterogeneous oxidation (gas-catalytic interaction), and iii) the elemental mercury that was not retained in the sorbent $\left(\mathrm{Hg}^{0}\right)$. $\mathrm{The} \mathrm{Hg}^{2+}$ at the outlet of the reactor was determined by capturing it in an ion exchanger resin suitable for the selective extraction of $\mathrm{Hg}^{2+}$ species [28]. A resin bed was placed after the reactor in each mercury experiment which was then directly analyzed by means of AMA. The $\mathrm{Hg}^{2+}$ from homogeneous oxidation is the result of an analysis of the resin without the catalyst, whereas the $\mathrm{Hg}^{2+}$ from heterogeneous oxidation is the amount of 
$\mathrm{Hg}^{2+}$ retained in the resin after the reactor with the catalyst. $15 \pm 3 \%$ of the $\mathrm{Hg}^{2+}$ was produced by homogeneous oxidation in both the simulated oxy-combustion and air combustion atmospheres (dotted line in Figures 4-5). The oxidation of $\mathrm{Hg}$ increased significantly in the presence of the $\mathrm{V} / \mathrm{W} / \mathrm{TiO}_{2}$ and Fe/Zeolite catalysts in both atmospheres. However, in the oxy-combustion atmosphere the oxidation was higher $(\sim 80 \%)$ and mercury retention was negligible (Figure 4$)$.

Apart from the mercury oxidation reactions, the possibility that mercury might be retained in the catalyst also needs be considered. The highest percentage of mercury retained in the sorbent $(\sim 20 \%)$, represented as $\mathrm{Hgp}$, was achieved by $\mathrm{V} / \mathrm{W} / \mathrm{TiO}_{2}$ in the conventional air coal combustion atmosphere (Figure 5). Wang et al. [11] proposed several reactions to explain mercury retention via mercury oxidation involving $\mathrm{V}_{2} \mathrm{O}_{5}, \mathrm{O}_{2}$ and $\mathrm{CO}_{2}$. However, in the present study, the catalyst-gas contact time was less than 1 second, implying that kinetic limitations in the reaction between $\mathrm{Hg}$ and $\mathrm{V}_{2} \mathrm{O}_{5}$ must be the cause of the low level of mercury removal, to the point where it was almost zero in oxy-fuel conditions. In the air combustion atmosphere differences became apparent when the catalyst was doped with $\mathrm{Mn}$. The presence of Mn increased the oxidation of $\mathrm{Hg}$ but led to a decrease in mercury retention capacity. This was not altogether unexpected because the previous results obtained from the characterization of these catalysts [27] indicated a loss of BET surface area which would result in a decrease in mercury capture on the solid. It is to be noted that the distribution of mercury species was similar with either catalyst in the oxy-combustion atmosphere (Figure 4). It can be inferred, therefore, that the differences in the characteristics of the catalysts were eclipsed by the effect of the flue gas composition. In the oxy-combustion atmosphere $\mathrm{Hg}^{2+}$ was the main mercury species. A slightly lower NOx conversion was observed in the oxy-combustion atmosphere than in the conventional air combustion atmosphere 
(Figures 2-3). The lower NOx conversion leaves more $\mathrm{NH}_{3}$ free making it more difficult for the catalyst to oxidize the mercury [32-33]. However, the effect of $\mathrm{NH}_{3}$ depends, among other factors, on the space velocity [32], the effect of $\mathrm{NH}_{3}$ being low at a low space velocity $\left(1.38 \mathrm{~s}^{-1}\right)$ [32]. In the present study the space velocity was $<0.1 \mathrm{~s}^{-1}$. Therefore, the higher $\mathrm{Hg}$ oxidation observed in the oxy-combustion than in the air combustion atmosphere (Figures 4-5) is a consequence of the fact that the lower NOx conversion results in a higher concentration of NOx in the flue gas which, in turn, favors $\mathrm{Hg}$ homogeneous oxidation through Reactions 3 and 4 [9].

$$
\begin{aligned}
& 2 \mathrm{Hg}^{0}(\mathrm{~g})+2 \mathrm{NO}(\mathrm{g}) \rightarrow 2 \mathrm{HgO}(\mathrm{g})+\mathrm{N}_{2}(\mathrm{~g}) \\
& \mathrm{Hg}^{0}(\mathrm{~g})+\mathrm{NO}_{2}(\mathrm{~g}) \rightarrow \mathrm{HgO}(\mathrm{g})+\mathrm{NO}(\mathrm{g})
\end{aligned}
$$

Moreover, the large proportion of $\mathrm{CO}_{2}$ might also be competing for the same adsorption sites as the mercury which would explain why the catalyst retained almost no mercury in the oxy-combustion atmosphere.

\section{Conclusions}

A comparison of the capacities of SCR catalysts to oxidize and capture mercury in simulated atmospheres of air and oxy-combustion showed that a greater level of mercury oxidation was produced in the enriched- $\mathrm{CO}_{2}$ atmosphere in the experimental conditions of this study. The results suggest that in an atmosphere enriched in $\mathrm{CO}_{2}$ the conversion of NOx is lower than in an atmosphere enriched in $\mathrm{N}_{2}$, leaving more NO and $\mathrm{NO}_{2}$ free to homogeneously oxidize mercury. Although kinetic limitations must also be taken into consideration, it can be inferred that in oxy-combustion conditions the presence of a large amount of $\mathrm{CO}_{2}$ decreases the number of active sites available for mercury adsorption. In these conditions, the different natures of the active sites of 
catalysts based on $\mathrm{V} / \mathrm{W} / \mathrm{TiO}_{2}$ or $\mathrm{Fe} /$ Zeolite with/without $\mathrm{Mn}$ are eclipsed by the effect of the flue gas composition.

\section{Acknowledgments}

The financial support for this work was provided by the National Research Program under project CTM2011-22921. The authors thank Johnson Matthey for supplying the catalysts employed in this study and PCTI Asturias for awarding Ms. Nuria FernandezMiranda a pre-doctoral fellowship.

\section{References}

[1] L. Zheng, Oxy-Fuel Combustion for Power Generation and Carbon Dioxide (CO2) Capture, Woodhead Publishing Series in Energy, ISBN: 978-1-84569-671-9, 2011, $400 \mathrm{pp}$.

[2] G. Scheffknecht, L. Al-Makhadmeh, U. Schnell, J. Maier, Oxy-fuel coal combustion-A review of the current state-of-the-art, Int. J. Greenhouse Gas Control $5(2011) 16-35$.

[3] Y. Mitsui, N. Imada, H. Kikkawa, A. Katagawa, Study of Hg and SO3 behavior in flue gas of oxy-fuel combustion system, Int. J. Greenhouse Gas Control 5 (2011) 143-150.

[4] B. Roy, W.L. Choo, S. Bhattacharya, Prediction of distribution of trace elements under oxy-fuel combustion condition using Victorian brown coals, Fuel 114 (2013) $135-142$.

[5] J.B. Bessone, The activation of aluminium by mercury ions in non-aggressive media, Corros. Sci. 48 (2006) 4243-4256. 
[6] S.O. Santos, IEA Greenhouse. Gas R\&D Programme Cheltenham, MEC7 Workshop DLCS, Strathclyde University, United Kingdom, 2010.

[7] J.H. Pavlish, L.L. Hamre, Y. Zhuang, Mercury control technologies for coal combustion and gasification systems, Fuel 89 (2010) 838-847.

[8] R. Spörl, Flue Gas Impurities, their impact and control under oxy-fuel conditions, $5^{\text {th }}$ Oxy-Fuel Capacity Building Course, Ponferrada, Spain $9^{\text {th }}, 2013$.

[9] N. Fernández-Miranda, M.A. Lopez-Anton, M. Díaz-Somoano, M.R. MartinezTarazona, Effect of oxy-combustion flue gas on mercury oxidation, Environ. Sci. Technol. 48 (2014) 7164-7170.

[10] R. Spörl, J. Maier, L. Belo, K. Shah, R. Stanger, T. Wall, G. Scheffknecht, Mercury and SO3 emissions in oxy-fuel combustion, Energy Procedia 63 (2014) $386-402$.

[11] F. Wang, G. Li, B. Shen, Y. Wang, C. He, Mercury removal over the vanadiatitania catalyst in CO2-enriched conditions, Chem. Eng. J. 263 (2015) 356-363.

[12] F. Normann, K. Andersson, B. Leckner, F. Johnsson, Emission control of nitrogen oxides in the oxy-fuel process, Prog. Energ. Combust. 35 (2009) 385-397.

[13] H. Gutberlet, A. Schluten, A. Lienta, SCR impacts on mercury emissions on coalfired boilers, EPRI`s SCR Workshop, Memphis, Tennessee, 2000.

[14] J. Kilgroe, C. Senior, Fundamental Science and Engineering of Mercury Control in Coal-fired Power Plants, Air Quality IV Conference, Arlington, VA, 2003.

[15] D.W. Lee, B.R. Yoo, Advanced metal oxide (supported) catalysts: Synthesis and applications, J. Ind. Eng. Chem. 20 (2014) 3947-3959.

[16] L. Qu, C. Li, G. Zeng, M. Zhang, M. Fu, J. Ma, F. Zhan, D. Luo, Support modification for improving the performance of $\mathrm{MnOx}-\mathrm{CeO} / \gamma-\mathrm{Al} 2 \mathrm{O} 3$ in selective catalytic reduction of NO by NH3, Chem. Eng. J. 242 (2014) 76-85. 
[17] J. Li, H. Chang, L. Ma, J. Hao, R.T. Yang, Low-temperature selective catalytic reduction of NOx with $\mathrm{NH} 3$ over metal oxide and zeolite catalysts-A review, Catal. Today 175 (2011) 147-156.

[18] X. Cheng, X.T. Bi, A review of recent advances in selective catalytic NOx reduction reactor technologies, Particuology 16 (2014) 1-18.

[19] M.B. Toftegaard, J. Brix, P.A. Jensen, P. Glarborg, A.D. Jensen, Oxy-fuel combustion of solid fuels, Prog. Energ. Combust. 36 (2010) 581-625.

[20] D. Fleig, K. Andersson, F. Normann, F. Johnsson, $\mathrm{SO}_{3}$ formation under oxy-fuel combustion conditions, Ind. Eng. Chem. Res. 50 (2011) 8505-8514.

[21] J. Ahn, R. Okerlund, A. Fry, E.G. Eddings, Sulfur trioxide formation during oxycoal combustion. Int. J. Greenhouse Gas Control 5 (2011) 127-135.

[22] J.R. Kenney, M.M. Clrak, A.A. Levasseur, S.G. Kang, SO3 emissions from a tangentially fired pilot scale boiler operating under oxy-combustion conditions, IEA GHG Special Workshop on Oxyfuel Combution, London, UK, January $26^{\text {th }}, 2011$.

[23] M. Klostermann, Efficiency increase of the oxyfuel process by waste heat recovery considering the flue gas treatment, In: $3^{\text {rd }}$ workshop of the IEA GHG international oxy-combustion network. Yokohama, Japan, March 5-6, 2008.

[24] Z. Sheng, Y. Hu, J. Xue, X. Wang, W. Liao, SO2 poisoning and regeneration of Mn-Ce/TiO2 catalyst for low temperature NOx reduction with NH3, J. Rare Earth. 30 (2012) 676-682.

[25] L. Hailong, L. Ying, W. Chang-Yu, Z. Junying, Oxidation and capture of elemental mercury over $\mathrm{SiO}_{2}-\mathrm{TiO}_{2}-\mathrm{V}_{2} \mathrm{O}_{5}$ catalysts in simulated low-rank coal combustion flue gas, Chem. Eng. J 169 (2011) 186-193. 
[26] Y. Zhuang, J. Laumb, R. Liggett, M. Holmes, J.H. Pavlish, Impacts of acid gases on mercury oxidation across SCR catalyst, Fuel Process. Technol. 88 (2007) 929934.

[27] Report High Capacity Sorbents and Optimisation of Existing Pollution Control Technology for Mercury Capture in Industrial Combustion Systems. Project RFCRCT-2007-00007; p44, 2011. Available in: http://cordis.europa.eu/project/rcn/87193_en.html

[28] A. Fuente-Cuesta, M. Díaz-Somoano, M.A. López-Antón, M.R. MartínezTarazona, Oxidised mercury determination from combustion gases using an ionic exchanger, Fuel 122 (2014) 218-222.

[29] M.J. Tang, R.A. Cox, M. Kalberer, Compilation and evaluation of gas phase diffusion coefficients of reactive trace gases in the atmosphere: volume 1. Inorganic compounds, Atmos. Chem. Phys. 14 (2014) 9233-9247.

[30] E.N. Fuller, P.D. Schettler, J.C. Giddings, New method for prediction of binary gas-phase diffusion coefficients, Ind. Eng. Chem. 58 (1966) 18-27.

[31] M. Rallo, B. Heidel, K. Brechtel, M.M. Maroto-Valer, Effect of SCR operation variables on mercury speciation, Chem. Eng. J. 198-199 (2012) 87-94.

[32] C. Richardson, T. Machalek, S. Miller, C. Dene, R. Chang, Effect of NOx Control Processes on Mercury Speciation in Utility Flue Gas, J. Air Waste Manage. Assoc. 52 (2002) 941-947.

[33] Y. Gao, Z. Zhang, J. Wu, L. Duan, A. Umar, L. Sun, Z. Guo, Q. Wang, A Critical Review on the Heterogeneous Catalytic Oxidation of Elemental Mercury in Flue Gases, Environ. Sci. Technol. 47 (2013) 10813-10823. 


\section{Figure captions}

Figure 1. Schematic diagram of the experimental device for (A) NOx reduction and (B) $\mathrm{Hg}$ retention and oxidation.

Figure 2. Performance of the SCR catalysts at $350^{\circ} \mathrm{C}$ on $\mathrm{NO}$ conversion in different flue gas compositions.

Figure 3. Performance of the SCR catalysts at $350^{\circ} \mathrm{C}$ on $\mathrm{NO}_{2}$ conversion in different flue gas compositions.

Figure 4. Percentages of mercury retained in the catalysts (Hgp), oxidized mercury $\left(\mathrm{Hg}^{2+}\right)$ and elemental mercury $\left(\mathrm{Hg}^{0}\right)$ in an oxy-combustion atmosphere.

Figure 5. Percentages of mercury retained in the catalysts (Hgp), oxidized mercury $\left(\mathrm{Hg}^{2+}\right)$ and elemental mercury $\left(\mathrm{Hg}^{0}\right)$ in an air coal combustion atmosphere. 
Table 1. The composition of the main atmospheres evaluated

\begin{tabular}{l|c|c|c}
\hline & Oxy-combustion & Air-combustion & $\mathrm{NOx}+\mathrm{NH}_{3}+\mathrm{O}_{2}$ \\
\hline $\mathrm{CO}_{2}$ & $64 \%$ & $20 \%$ & ------ \\
$\mathrm{N}_{2}$ & $20 \%$ & $70 \%$ & balance \\
$\mathrm{H}_{2} \mathrm{O}$ & $12 \%$ & $6 \%$ & ----- \\
$\mathrm{O}_{2}$ & $4 \%$ & $4 \%$ & $4 \%$ \\
$\mathrm{SO}_{2}$ & $1000 \mathrm{ppm}$ & $1000 \mathrm{ppm}$ & ---- \\
$\mathrm{NO}$ & $600 \mathrm{ppm}$ & $600 \mathrm{ppm}$ & $600 \mathrm{ppm}$ \\
$\mathrm{NO}_{2}$ & $100 \mathrm{ppm}$ & $100 \mathrm{ppm}$ & $100 \mathrm{ppm}$ \\
$\mathrm{HCl}$ & $25 \mathrm{ppm}$ & $25 \mathrm{ppm}$ & ----- \\
$\mathrm{NH}_{3}$ & $1000 \mathrm{ppm}$ & $1000 \mathrm{ppm}$ & $1000 \mathrm{ppm}$ \\
\hline
\end{tabular}




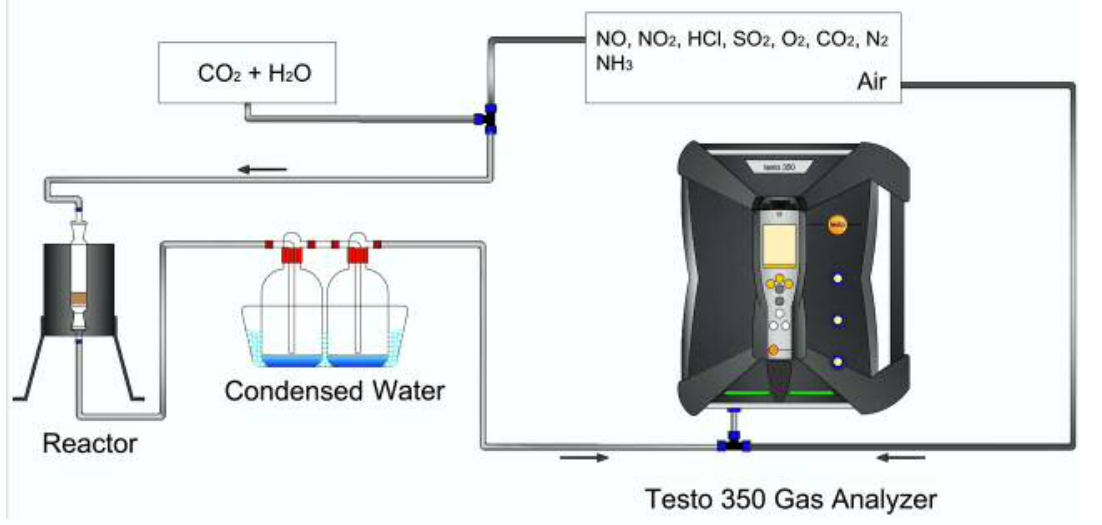

(A)

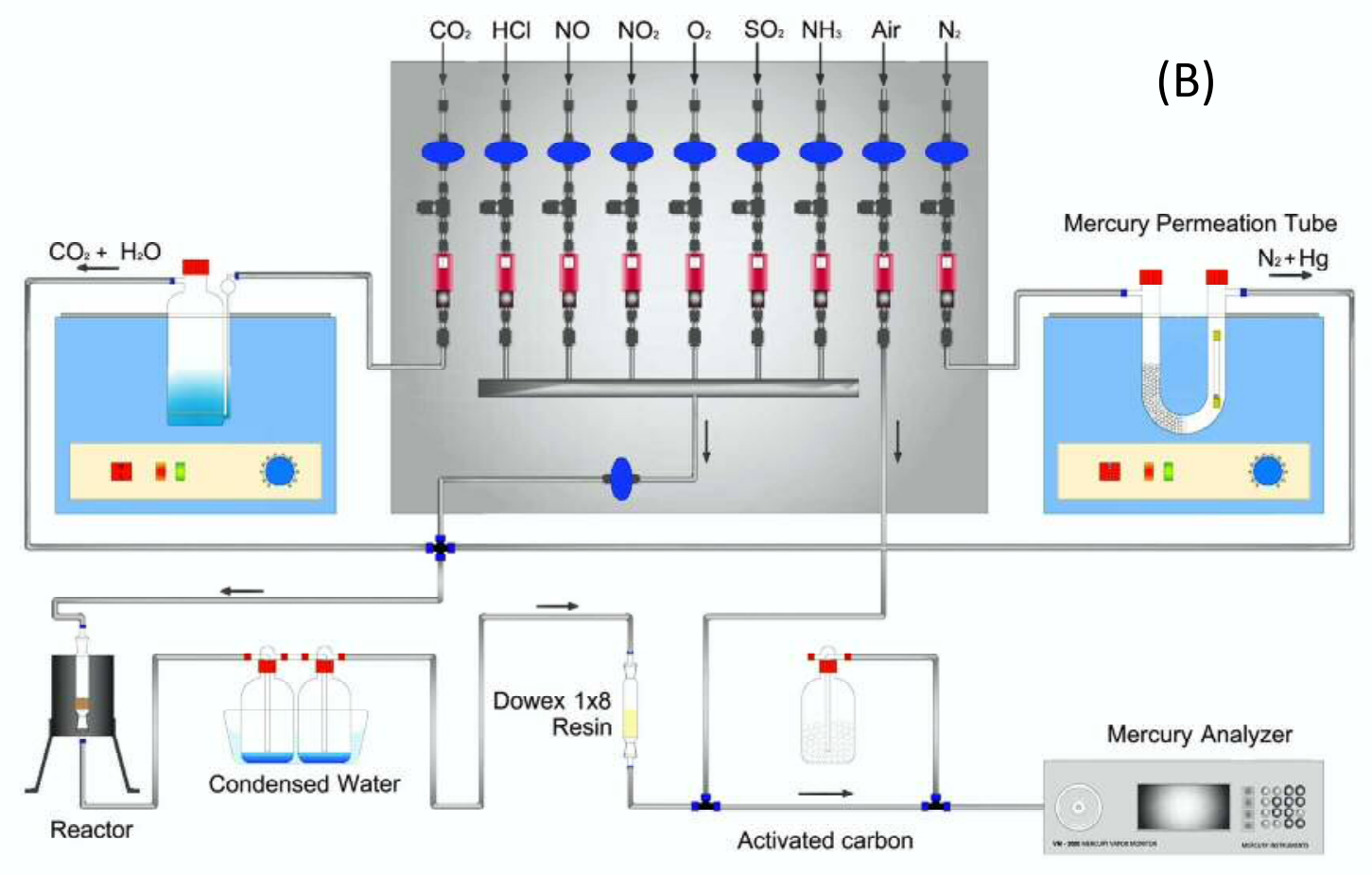

Figure 1 
NO Reduction

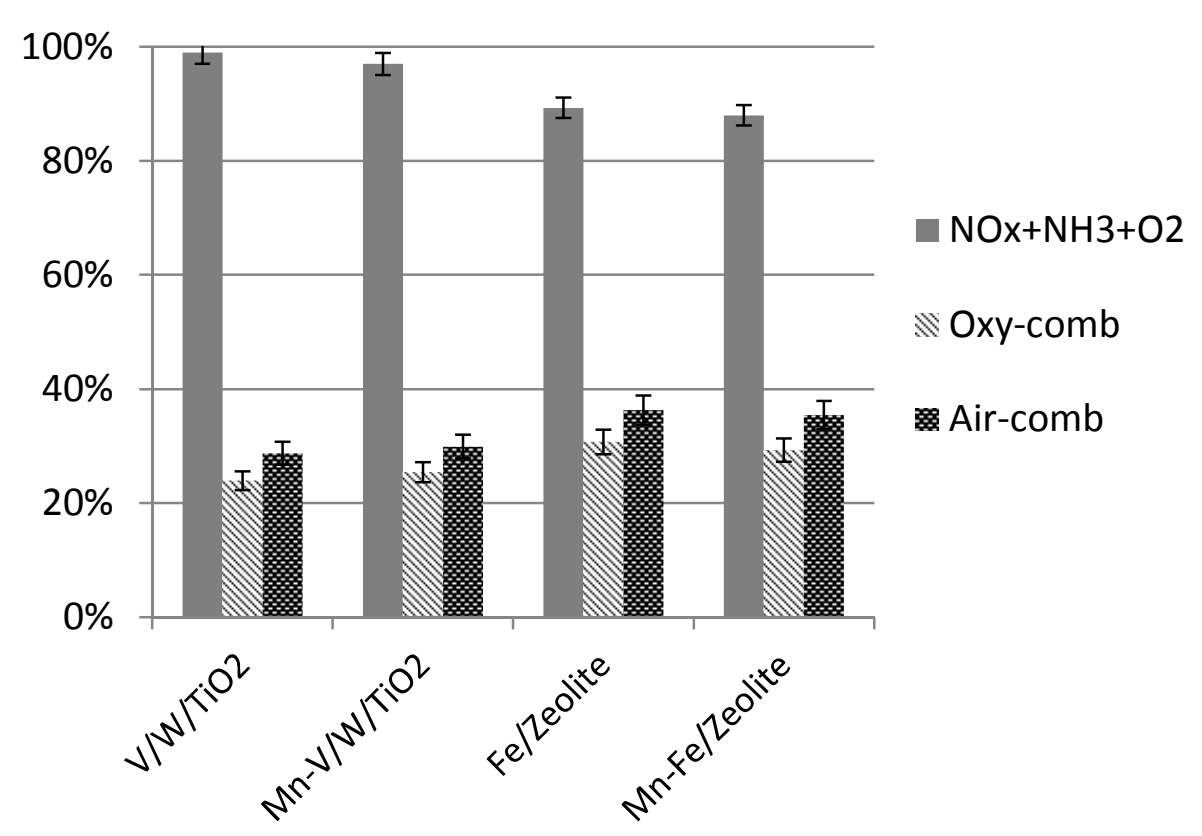

Figure 2

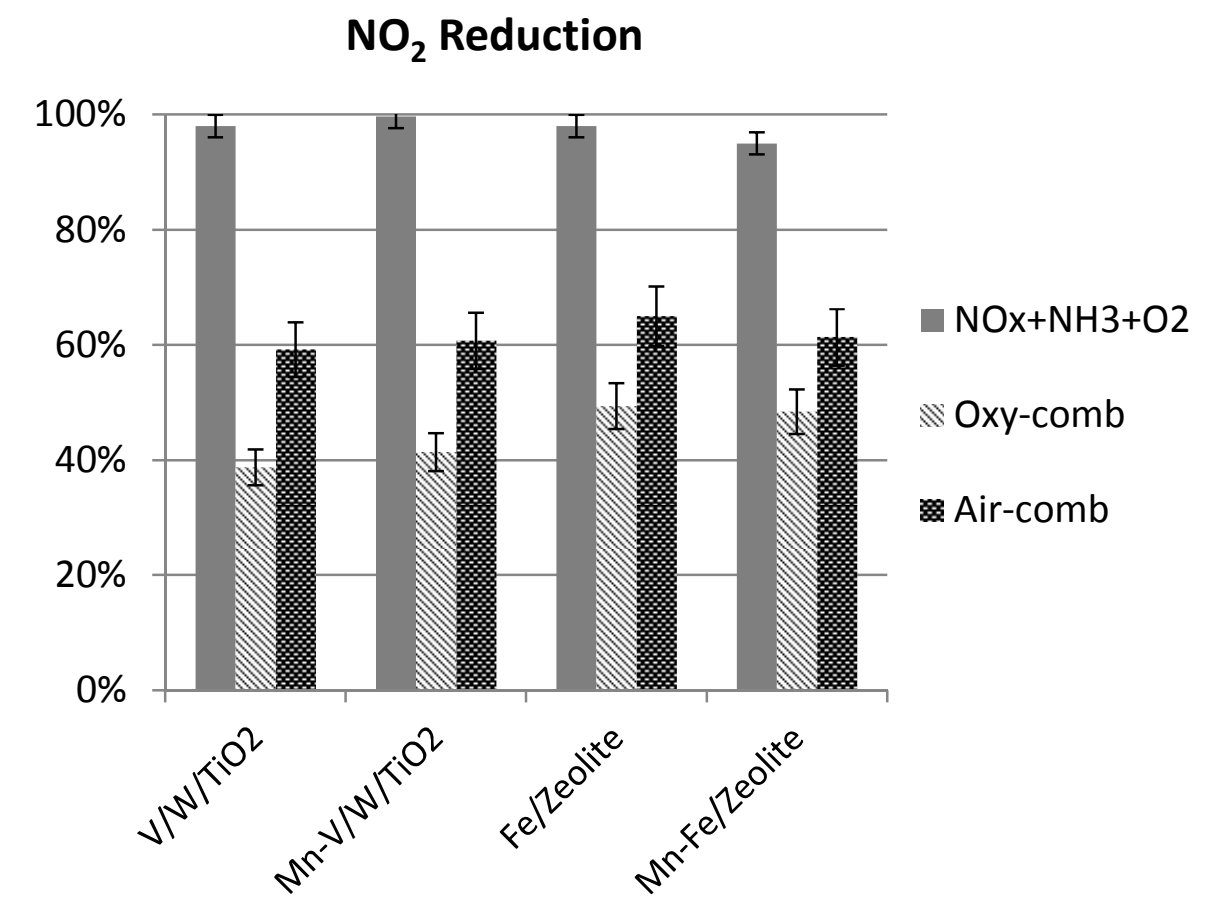

Figure 3 


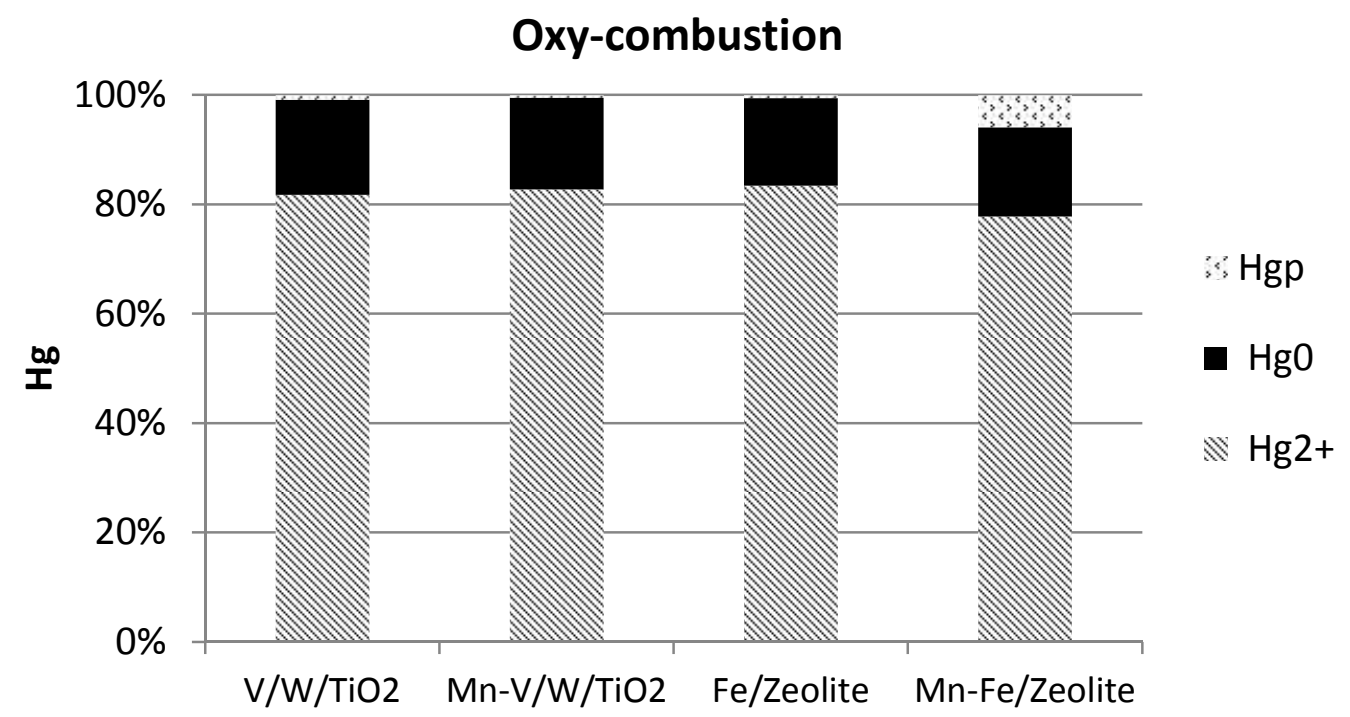

Figure 4

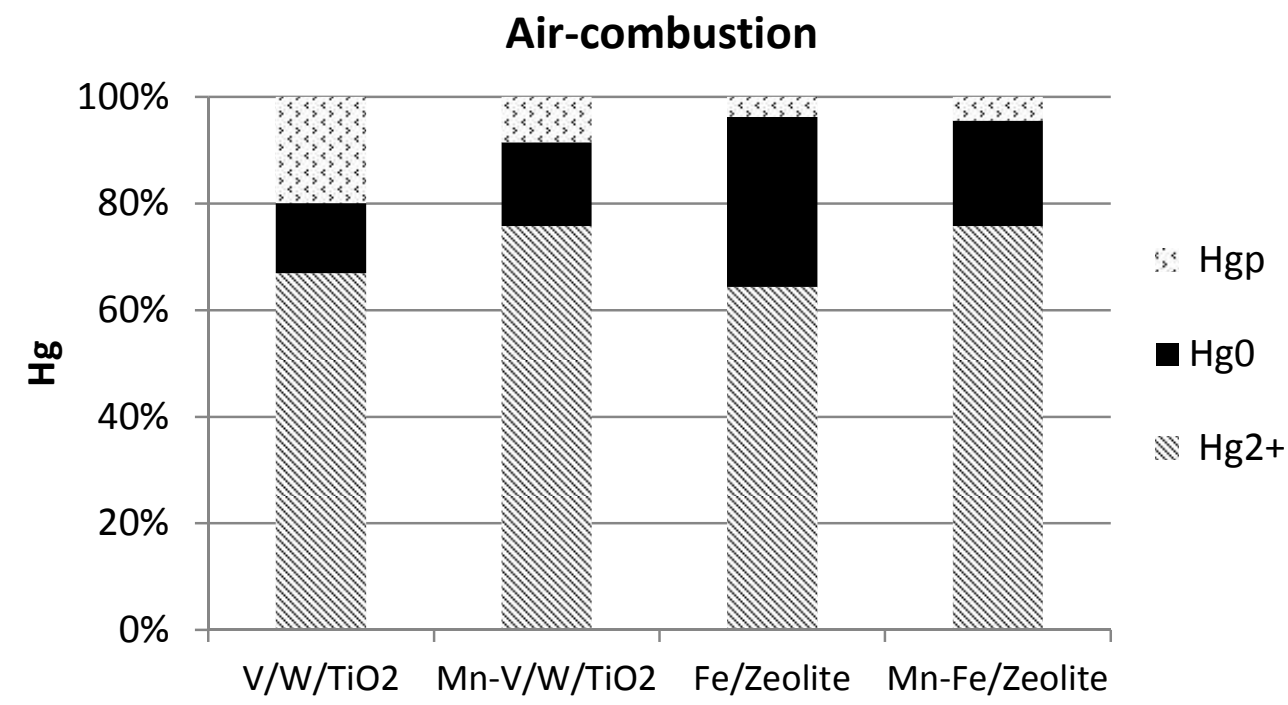

Figure 5 